\title{
CNS Injury and Helmets
}

Can. J. Neurol. Sci. 2001; 28: 2-3

In this issue of The Canadian Journal of Neurological Sciences, Hentschel and colleagues have provided a detailed look at the types of head injuries encountered in skiers and snowboarders throughout British Columbia. Their results suggest a proportionately higher risk of serious head injury in snowboarders compared to skiers, as evidenced by a higher rate of skull fracture and a higher rate of coma (GCS < 8) on presentation to hospital. Additionally, a greater percentage of skiers with head injuries were able to return home from hospital, and a greater percentage of skiers were neurologically normal on discharge compared to snowboarders with head injuries. Despite the relatively small numbers involved, and the lack of a denominator with which to establish an overall head injury rate, the authors have made a very compelling argument that snowboarding may be considerably more dangerous than skiing. The lack of helmet use in both groups is especially disturbing.

For those of us who work in the Neurological Sciences, and in particular for those of us who are directly involved in patient care, issues surrounding helmet protection take on a highly charged, personal and often emotional flavor. The human tragedy regularly encountered in our emergency and operating rooms repeatedly justifies our convictions about the usefulness of helmets. The fuse igniting our intolerance and impatience over helmet abstinence becomes ever shorter as we repeatedly hear excuses of lack of supervision, fashion concerns, and even arguments over "freedom of choice".

I remember an incident that occurred when I first started my neurosurgical practice in 1996. A 22-year-old university student had been roller-blading on one of the paved paths running alongside the Bow River. Qui-Lynn (not her real name) had moved to Calgary from Asia a year earlier to undertake her postsecondary education. She had been doing well in her studies. In the summer of 1996, Qui-Lynn had taken up the sport that so many of her classmates seemed to enjoy, especially during the nice weather: in-line skating. On the July evening that I was to meet her, she had been with a friend, trying to solve the "wobbliness" so common to a newcomer in this activity. At about 8:30 p.m., as Qui-Lynn recovered her posture by a bridge across the river, standing up from a near fall, both feet somehow, inexplicably, shot out in front of her. The end result was to leave her flat on her back, about 1.5 metres in the air, staring upwards into what, that evening, was a calm, deep-blue summer sky. Even now, four years later, I often wonder what Qui-Lynn might have been thinking as she fell back to the ground. Whatever her thoughts were, they were certainly her last as the back of her unhelmeted head met the pavement.

When I met Qui-Lynn in the trauma bay, about a half hour later, she was already intubated. Outwardly she appeared as a vital young adult, healthy, ready to make the most of her life. I knew otherwise. Her blood pressure was high and both pupils were fixed and dilated. Mannitol was running. The CT scan showed a linear occipital skull fracture, a large posterior fossa epidural hematoma, and the absence of meaningful subarachnoid space. Despite an emergency craniotomy, Qui-Lynn was pronounced brain-dead 12 hours later. I never met her family. Another face. Another procedure. More carnage. More to come. It's the same every year.

We've all seen patients like this come and go. We've all seen

\section{Four-year-old boy killed when ATV flips}

\author{
The Canadian Press \\ WHITECOURT
}

A four-year-old boy was killed during the weekend when the all-terrain vehicle he was riding on flipped.

The child was with two adults on a four-by-four quad-runner when the machine flipped backwards onto the three riders, RCMP said.

The accident happened Saturday night near Whitecourt, about 50 kilometres northwest of Edmonton.

The adults had minor injuries.

None of the riders was wearing a helmet, police said. from: The Calgary Sun, September 7, 2000, p 15

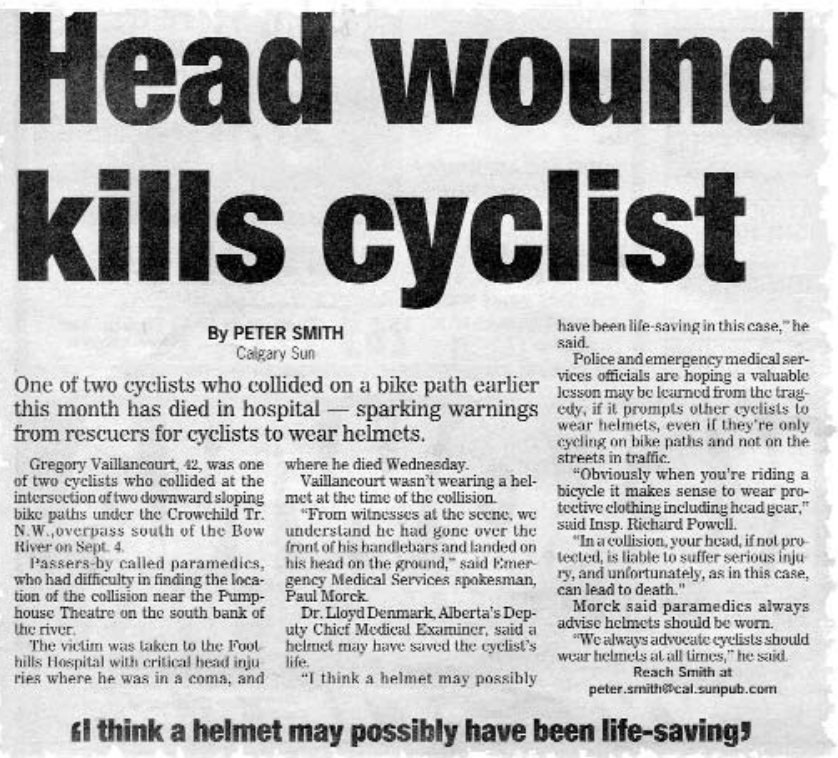


the grief and the tragedy surrounding such events. Many times, especially in high impact trauma, we know nothing could have reliably prevented the injury. However, several times each year we are faced with cases like this, that beyond a doubt, could have been prevented had the victim been wearing protective head gear. Can anyone deny us the anger and frustration that seems to boil over when we see adults and children riding bicycles, skiers and snowboarders darting in and out of trees, and skate-boarders challenging gravity, all without helmets? No, I don't think so.

The real question quickly becomes "how do we change the behavior of a society?" Looking at precedents such as automobile seat-belts, the answer appears to be through education and legislation. The former heightens awareness while the latter maximizes compliance. Of course the debate still rages about the efficacy of either. One thing is for sure: a prospective randomized trial to provide indisputable Class I evidence about helmet efficacy is not forthcoming.

Can we channel our frustrations into constructive energy? Who has the time to take away from a busy career to speak to special interest groups or to write their MLA? When we do get around to these activities, who listens? It seems doubly frustrating when proactive efforts fall on silent ears and closed eyes. Adults tell their children that they never wore helmets and somehow they survived their childhood. Politicians whimper that the issue is too controversial, fearing for their jobs rather than pushing for the safety of their constituents.

Slowly though, attitudes do seem to be changing. Thirty years ago seat-belt legislation didn't exist, let alone helmet legislation. Over the past decade several provinces have adopted helmet laws pertaining to bicycle use. Even without laws, more people across the country wear helmets today in all types of sports and recreation than did ten years ago. So, despite our frustrations, somehow the message is getting out. We have to keep the momentum going. Individually our efforts seem despairingly futile; collectively though it is possible to make a difference.

When speaking in public about helmet use, the arguments put forward by opponents eventually become repetitious. The most difficult to address, in my experience, has been the debate over freedom of choice. People will argue that government involvement is already too pervasive in society; it threatens to enter every facet of our lives. The same individuals also challenge you to define where legislation should end and common sense should take over. Both positions appeal to our own sense of appropriateness and therefore become hard to rebut, at least directly. The faulty logic in these arguments lies within the term "common sense". To not wear a helmet is to demonstrate a lack of common sense. In this instance, freedom of choice is essentially a mechanism to opt out of common sense. The easiest way I have found to handle these convictions is not through logic (there can't be logic where there is no common sense), but through an arbitration role as gatekeepers of the medical system. Individuals in the "anti-helmet" camp seem much less prone to exercise their freedom of choice to forgo helmet use if, in a hypothetical health care system, they become required to assume financial liability for the medical expenses incurred by themselves or their children as a result of head injury. It is attractive to counter right-to-choose attitudes with a "just" medical system in which a degree of responsibility for personal health care rests with the individual at risk. Only in this setting does the term "common sense" begin to take on significance. After all, in deciding not to wear a helmet, a common-sensed individual should be prepared to accept all consequences (personal and financial)!

The purpose of this editorial was not to provide another review of the literature and then wield the scientific sword in favor of helmet use. As Hentschel and colleagues have demonstrated with skiers and snowboarders, the evidence continues to speak for itself. Appended is a list of additional articles, compiled over the last two years, for those inclined to pull them including a Cochrane review. ${ }^{1-13}$ Instead, this editorial is intended to focus our despair and frustration over the tragedy that continues to accumulate. Tragedy that we all know can be prevented. These convictions and emotions should incite us, as a community, into further action through both education and political reform. We must step outside the traditional role of the caregiver. Our mission is not only to further science and fact, but to set an example through wearing helmets ourselves, to talk to our neighborhood schools, to educate ski patrollers, to meet with local and provincial interest groups, and to hound politicians. Participation in local or national groups such as Think First can make our efforts more efficient. Above all else, we can't be silent.

RJ Hurlbert Calgary, Alberta

\section{REFERENCES}

1. Borglund ST, Hayes JS, Eckes JM. Florida's bicycle helmet law and a bicycle safety educational program: did they help? J Emerg Nurs 1999;25(6):496-500.

2. Chiu WT, Kuo CY, Hung CC, Chen M. The effect of the Taiwan motorcycle helmet use law on head injuries. Am J Public Health 2000;90(5):793-796.

3. Delaney JS, Drummond R. Has the time come for protective headgear for soccer? Clin J Sports Med 1999;9(3):121-123.

4. Hackam DJ, Kreller M, Pearl RH. Snow-related recreational injuries in children: assessment of morbidity and management strategies. J Pediatr Surg 1999;34(1):65-68.

5. Hitosugi M, Takatsu A, Shigeta A. Injuries of motorcyclists and bicyclists examined at autopsy. Am J Forensic Med Pathol 1999; 20(3):251-255.

6. Jackson H. Cycle helmets. BMA report does not give the whole picture. Br Med J 1999;319(7216):1071-1072.

7. Loubeau PR. Exploration of the barriers to bicycle helmet use among 12 and 13 year old children. Accid Anal Prev 2000;32(1): 111-115.

8. Naunheim RS, Standeven J, Richter C, Lewis LM. Comparison of impact data in hockey, football, and soccer. J Trauma-Inj Infect Crit Care 2000;48(5):938-941.

9. Puder DR, Visintainer P, Spitzer D, Casal D. A comparison of the effect of different bicycle helmet laws in 3 New York City suburbs. Am J Public Health 1999;89(11):1736-1738.

10. Rees-Jones A. Skiing helmets. Br J Sports Med 1999;33(1):3.

11. Rice MR, Alvanos L, Kenney B. Snowmobile injuries and deaths in children: a review of national injury data and state legislation. Pediatrics 2000;105(3 Pt 1):615-619.

12. Sorli JM. Equestrian injuries: a five year review of hospital admissions in British Columbia, Canada. Inj Prev 2000;6(1):59-61.

13. Thompson DC, Rivara FP, Thompson R. Helmets for preventing head and facial injuries in bicyclists. Cochrane Database of Systematic Reviews [computer file] 2000;(2):CD001855.

14. Tsai MC, Hemenway D. Effect of the mandatory helmet law in Taiwan. Inj Prev 1999;5(4):290-291.

15. Wesson D, Spence L, Hu X, Parkin P. Trends in bicycling-related head injuries in children after implementation of a communitybased bike helmet campaign. J Pediatr Surgery 2000;35(5):688689. 